\title{
MicroRNA-497 upregulation inhibits cell invasion and metastasis in T24 and BIU-87 bladder cancer cells
}

\author{
ZHIYONG WEI ${ }^{1}$, XIAOFENG HU ${ }^{2}$, JUNJIE LIU ${ }^{3}$, WENBIN ZHU ${ }^{4}$, XUEMEI ZHAN ${ }^{1}$ and SHUHONG SUN ${ }^{2}$ \\ Departments of ${ }^{1}$ Pathology and ${ }^{2}$ Clinical Laboratory, Linyi People's Hospital, Linyi, Shandong 276003; \\ ${ }^{3}$ Department of Pathology, Chinese Medicine Hospital in Linyi City, Linyi, Shandong 276000; ${ }^{4}$ Department \\ of Urinary Surgery, Linyi People's Hospital, Linyi, Shandong 276003, P.R. China
}

Received March 29, 2016; Accepted March 13, 2017

DOI: $10.3892 / \mathrm{mmr} .2017 .6805$

\begin{abstract}
Previous studies have reported the crucial role of microRNAs (miRNAs) in the biology and tumorigenesis of various types of cancer, including bladder cancer. The present study aimed to investigate the importance of miRNA (miR)-497 on the pathogenesis of bladder cancer. A total of 50 patients diagnosed with bladder cancer were enrolled in the current study. The expression levels of miR-497 in the cancerous and the adjacent noncancerous tissues were detected using reverse transcription-quantitative polymerase chain reaction. The association between miR-497 expression and various parameters, including age, tumor-node-metastasis (TNM) stage and pathological classification was determined. An miR-497-overexpressing vector was transfected into the T24 and BIU-87 bladder cancer cell lines in order to determine the effect of miR-497 expression on cell migration and invasion using Transwell assays. Additionally, the cell migration and invasion-associated protein expression levels were also analyzed using western blotting. The findings of the present study revealed that miR-497 was expressed at low levels in the cancer bladder tissue compared with the adjacent noncancerous tissue, and its expression was associated with the pathological classification, TNM stage and metastasis. Additionally, miR-497 overexpression significantly reduced the number of migrated and invasive T24 and BIU-87 cells. The mRNA and protein expression levels of E-cadherin were increased, whereas levels of vimentin and $\alpha$-smooth muscle actin were reduced following miR-497 overexpression. The present study revealed that miR-497 overexpression may be a suppressor of the metastasis of bladder cancer, and may have an important role in the diagnosis of bladder cancer.
\end{abstract}

Correspondence to: Dr Shuhong Sun, Department of Clinical Laboratory, Linyi People's Hospital, 27 Jiefang Road, Linyi, Shandong 276003, P.R. China

E-mail: sunshuhong0767@126.com

Key words: bladder cancer, microRNA-497, cell migration, cell invasion, metastasis-associated proteins

\section{Introduction}

Bladder cancer remains one of the common urinary system malignancies worldwide, with a high mortality rate (1). A previous study estimated that $\sim 90 \%$ of bladder cancers are transitional cell bladder carcinomas (2). It has been reported that accurate staging and precise pathologic evaluation are important for optimization of the correct bladder cancer treatment regimens (3). At present, diagnosis for bladder cancer remains unsatisfactory, primarily due to the high cost, high false-positive rate, poor sensitivity and the delay in result availability $(3,4)$. Therefore, the identification of several biomarkers for the diagnosis of bladder cancer will greatly contribute to the improvement of clinical diagnosis and treatment of bladder cancer.

MicroRNAs (miRNAs) are highly conserved endogenous non-coding RNAs of 20-22 nt in length that function in various biological processes at the transcriptional or post-transcriptional level by targeting the 3'-untranslated region of mRNA (5). Previous studies have demonstrated that various miRNAs are involved in the progression and biology of tumorigenesis (6,7). For example, miRNA (miR)-490-5p has been reported to function as a novel tumor suppressor in human bladder cancer by targeting c-Fos (8), and miR-27a downregulation may lead to cisplatin resistance in bladder cancer (9). Previous studies have reported that miR-497 has an important role in certain diseases, including tumor and brain diseases, such as cerebral ischemia, through complex mechanisms $(10,11)$. Additionally, Yan et al (12) previously reported that miR-497 prevents angiogenesis and metastasis of hepatocellular carcinoma by regulation of astrocyte elevated gene-1 and vascular endothelial growth factor A (12). Likewise, previous studies have revealed that there may be a correlation between miR-497 expression levels and the development and metastasis of bladder cancer $(13,14)$.

The aim of the present study was to investigate the role of miR-497 expression in patients with bladder cancer and to determine the association between miR-497 expression and the metastasis and invasion of bladder cancer cells using T24 and BIU-87 cell lines. Various experimental methods were used to analyze the effect of abnormal miR-497 expression on bladder cancer cell migration and invasion and the expression of metastasis-associated proteins. The present study may 
provide a theoretical basis for the application of miR-497 in improving the diagnosis of bladder cancer.

\section{Materials and methods}

Patients. A total of 50 patients diagnosed with bladder cancer in Linyi People's Hospital (Linyi, China) between March 2013 and July 2014 were enrolled in the present study. A total of 34 cases were male and 16 cases were female and the mean age was $59.83 \pm 7.42$. All patients underwent surgery in Linyi People's Hospital; patients were diagnosed with urothelial bladder cancer using biopsy samples acquired prior to the surgery and postoperative pathology detection. The patients had not received any chemotherapy, radiation, or immunotherapy prior the surgery. The pathological classification was performed according to the WH01973 criteria (15) and tumor-node-metastasis (TNM) staging was based on the International Union against Cancer in 2002, version 6 of TNM stage (16). According to pathological classification (15), 29 cases were stage I (urothelium, high differentiation), 12 cases were stage II (urothelium, middle differentiation) and 9 cases were stage III (urothelium, low differentiation). The patient characteristics are described in Table I. Pathological tissues and the adjacent noncancerous tissues were extracted, based on histological analysis. The adjacent noncancerous tissues were taken $3 \mathrm{~cm}$ from the edge of the tumor and served as the control group. Tissues were subsequently snap frozen with liquid nitrogen and stored at $-80^{\circ} \mathrm{C}$ until RNA extraction. The procedures of the present study were approved by the Protection of Human Ethics Committee of Linyi People's Hospital (Linyi, China), and all patients provided signed written informed consent prior to the collection of clinical samples.

Cell culture and transfection. T24 and BIU-87 human bladder cancer cell lines and the SV-HUC-1 immortalized human bladder epithelium cells (all from the American Type Culture Collection, Manassas, VA, USA) were cultured in Dulbecco's modified Eagle's medium (Invitrogen; Thermo Fisher Scientific, Inc., Waltham, MA, USA) supplemented with $10 \%$ fetal calf serum (Gibco; Thermo Fisher Scientific, Inc.) in a cell culture incubator with $5 \% \mathrm{CO}_{2}$ at $37^{\circ} \mathrm{C}$. For the cell transfection, miR-497 mimics (sense: 5'-CAGCAGCACACUGUG GUUUGU-3'; antisense: 5'-AAACCACAGUGUGCUGCU GUU-3') and scramble control mimics (sense: 5'-UUCUCC GAACGUGUCACGUTT-3'; antisense: 5'-ACGUGACAC G UUCGGAGAATT-3') (GenePharma Co., Ltd., Shanghai, China) were transfected into the cells at a final concentration of $50 \mathrm{nM}$ using Lipofectamine ${ }^{\circledR} 2000$ reagent (Invitrogen; Thermo Fisher Scientific, Inc.).

Migration and invasion assay. Cell migration and invasion were conducted using Transwell migration chambers $(8-\mu \mathrm{m}$ pore size; Costar; Corning Incorporated, Corning, NY, USA) (17). Bladder cancer cells were seeded at a density of $5 \times 10^{4}$ cells/well in the upper portion of the chamber with serum-free medium following the transfection. Medium containing $10 \%$ fetal calf serum was used as a chemoattractant in the lower chamber. Following incubation at $37^{\circ} \mathrm{C}$ for $24 \mathrm{~h}$, non-migrated cells on the top of the membrane were scraped and removed with cotton swabs carefully. The migrated cells on the bottom of the membrane were subsequently fixed with $4 \%$ formaldehyde at room temperature for $15 \mathrm{~min}$, stained with Diff-Quik (Siemens Healthcare Diagnostics, Newark, DE, USA) and counted using a light microscope. The membranes for the invasion assay were coated with a diluted extracellular matrix solution (Sigma-Aldrich; Merck Millipore, Darmstadt, Germany), the remaining processes for cell treatment were the same as the aforementioned migration assay.

Reverse transcription-quantitative polymerase chain reaction. Total RNA extraction from the treated cells was conducted using TRIzol reagent (Invitrogen; Thermo Fisher Scientific, Inc.) as previously described (18), the extracts were treated with RNase-free DNase I (Promega Corporation, Madison, WI, USA). Subsequently, the concentration and purity of the isolated RNA were quantified using SMA400 UV-VIS (Merinton Instrument, Ltd., Shanghai, China). Purified RNA $(0.5 \mu \mathrm{g} / \mu \mathrm{l}$ in nuclease-free water) was used for cDNA synthesis with the PrimerScript First Strand cDNA Synthesis kit (Invitrogen; Thermo Fisher Scientific, Inc.). Expression levels of the targets were detected in an Eppendorf Mastercycler (Brinkman Instruments, Westbury, NY, USA) using the SYBR ExScript RT-qPCR kit (Takara Biotechnology Co., Ltd., Dalian, China). Melting curve analysis of amplification products was performed at the end of each PCR to confirm that only one product was amplified and detected. Relative expression of targets was calculated according to the $2^{-\Delta \Delta \mathrm{Cq}}$ method (19). GAPDH and U6 were chosen as the internal controls. Primers used for miR-497 amplification were designed by Biomics Biotechnology (Nantong, China), and primers for the other targets amplification are presented in Table II.

Western blotting. Cells cultured for $48 \mathrm{~h}$ in each group were lysed with radioimmunoprecipitation assay buffer (Sangon Biotech, Co., Ltd., Shanghai, China) containing phenylmethanesufonyl fluoride (Sigma-Aldrich; Merck Millipore) and the lysates were centrifuged at $14,000 \mathrm{x} g$ for $10 \mathrm{~min}$ at $4^{\circ} \mathrm{C}$. Supernatant was collected to quantify the protein concentrations using bicinchoninic acid protein assay kit (Pierce; Thermo Fisher Scientific, Inc.). Equal quantity of protein $(50 \mu \mathrm{g})$ per cell lysate was subjected to a $12 \%$ sodium dodecylsulfate-polyacrylamide gel electrophoresis and transferred onto a PVDF membrane (Merck Millipore). The PVDF membranes were blocked with Tris-buffered saline Tween-20 (TBST) containing 5\% non-fat milk for $1 \mathrm{~h}$ at room temperature. Subsequently, the membranes were incubated with rabbit anti-human primary antibodies for E-cadherin (ab15148), vimentin (ab45939) and a-smooth muscle actin ( $\alpha$-SMA; ab5694) (all from Abcam, Cambridge, UK) overnight at $4^{\circ} \mathrm{C}$. The membranes were incubated with horseradish-peroxidase labeled goat anti-rabbit secondary antibody (1:5,000 dilution; ab205718; Abcam) at room temperature for $1 \mathrm{~h}$. The PVDF membranes were washed three times with $1 \mathrm{X}$ TBST buffer for $10 \mathrm{~min}$. The signals were detected following incubation with a chromogenic substrate using enhanced chemiluminescence (GE Healthcare Life Sciences, Chalfont, UK). Additionally, GAPDH was used as the internal control.

Statistical analysis. All data were expressed as the mean \pm standard error of mean. Clinicopathologic data were 
analyzed using Student's t-test. Data presented in the figures were analyzed using one-way or two-way analysis of variance followed by Tukey's significant difference post hoc test. Analyses were performed using GraphPad Prism version 5.0 (GraphPad Software, Inc., La Jolla, CA, USA). P $<0.05$ was considered to indicate a statistically significant difference.

\section{Results}

Expression of miR-497 in bladder cancer cells. In order to analyze the expression of miR-497 in bladder cancer cells, patients with bladder cancer and the adjacent noncancerous tissues were collected. The findings of the present study determined that miR-497 expression was significantly reduced in the cancer tissues compared with the adjacent noncancerous tissues. Additionally, its expression was reduced gradually from cancer tissue stage I to stage III (Fig. 1A). Therefore, the expression of miR-497 may be negatively associated with the stage of bladder cancer. The expression level of miR-497 was significantly reduced in the cancer cells compared to the SV-HUC-1 normal uroepithelium cells $(\mathrm{P}<0.05$ in T24 cells; $\mathrm{P}<0.01$ in BIU-87 cells; Fig. 1B).

Association between miR-497 expression and patient characteristics. The association between miR-497 expression and pathological parameters of patients with bladder cancer was evaluated and presented in Table I. It was determined that there was no association between miR-497 expression and age or tumor diameter $(\mathrm{P}>0.05)$. However, miR-497 expression was lower in patients at stage II and III compared with patients at stage $\mathrm{I}(\mathrm{P}<0.05)$, indicating that miR-497 expression may be associated with tumor stage. Furthermore, miR-497 expression was downregulated in patients with lymph node metastasis or distant metastasis, compared with patients without metastasis $(\mathrm{P}<0.05)$, suggesting that miR-497 expression may be associated with the occurrence of metastasis.

Aberrant expression of miR-497 in bladder cancer cells after transfection. The T24 and BIU-87 cells were transfected with miR-497 mimic or scramble control mimics, followed by estimation of miR-497 expression. MiR-497 levels in T24 and BIU-87 cells were both markedly upregulated by transfection with miR-497 mimics, compared with cells transfected with scramble control mimics (both $\mathrm{P}<0.01$ ) (Fig. 2). MiR-497 expression level was not altered following transfection with scramble control mimics, compared with untreated cells. The data confirmed that miR-497 was upregulated following transfection with miR-497 mimics.

miR-497 overexpression suppresses cell migration and invasion. Based on the aforementioned findings, miR-497 expression may be associated with metastasis of bladder cancer. Therefore, the effect of miR-497 overexpression on cell migration and invasion was investigated (Fig. 3). The findings revealed that overexpression of miR-497 significantly reduced the number of migrated cells in T24 and the BIU-87 cells compared with the control miRNA ( $\mathrm{P}<0.01$; Fig. 3A). The number of invasive cells of both cell lines were also significantly reduced in the groups overexpressing miR-497 $(\mathrm{P}<0.01$; Fig. 3B). These findings indicated that overexpressed miR-497
Table I. Characteristics of patients enrolled in the present study.

\begin{tabular}{lrrr}
\hline Characteristic & $\mathrm{n}$ & miR-479 & P-value \\
\hline Age (years) & & & 0.637 \\
$\quad \leq 50$ & 29 & $5.027 \pm 0.765$ & \\
$>50$ & 21 & $4.926 \pm 0.711$ & \\
Diameter of tumor (cm) & & & 0.948 \\
$\quad \leq 2.5$ & 37 & $4.822 \pm 0.651$ & \\
$>2.5$ & 13 & $4.808 \pm 0.717$ & \\
Pathological stage & & & $<0.001$ \\
$\quad$ I & 29 & $7.121 \pm 0.702$ & \\
II/III & 21 & $4.988 \pm 0.547$ & \\
Lymph node metastasis & & & $<0.001$ \\
$\quad$ No & 17 & $13.023 \pm 0.912$ & \\
Yes & 33 & $6.875 \pm 0.772$ & \\
Distant metastasis & & & $<0.001$ \\
No & 12 & $14.159 \pm 0.512$ & \\
Yes & 38 & $7.485 \pm 0.661$ & \\
\hline
\end{tabular}

miR-479, microRNA-479.

may be associated with reduced migration and invasion of bladder cancer cells.

miR-497 expression was associated with migration and invasion-associated proteins. In order to investigate the underlying molecular mechanism for the influences of miR-497 expression on bladder cancer cell migration and invasion, the expression levels of migration and invasion-associated proteins was determined (Fig. 4). When miR-497 was overexpressed in T24 cells, the mRNA and protein expression level of E-cadherin was significantly increased $(\mathrm{P}<0.01)$, whereas vimentin and $\alpha$-SMA expression levels were significantly reduced $(\mathrm{P}<0.05$, Fig. $4 \mathrm{~A})$. The present study also determined that the alterations in E-cadherin, vimentin and $\alpha$-SMA expression levels were similar in BIU-87 and in T24 cells (Fig. 4B). These findings indicated that miR-497 expression is associated with migration and invasion through affecting the protein expression of epithelial-mesenchymal transition markers in bladder cells.

\section{Discussion}

Previous studies have demonstrated that miRNAs are important for the biology and tumorigenesis of various types of cancer. Previous research reported that miR-497 is involved in breast cancer malignancy (11), and another study demonstrated that miR-497 may inhibit angiogenesis and metastasis of hepatocellular carcinoma (20). However, investigations focusing on the relationship between miR-497 and bladder cancer are limited. The present study analyzed the expression of miR-497 in bladder cancer tissues and investigated the association between miR-497 expression and the metastasis of bladder cancer. The findings of the present study revealed 
Table II. Primers used for target amplification in the present study.

\begin{tabular}{lll}
\hline Target & \multicolumn{1}{c}{ Sense $\left(5^{\prime}-3^{\prime}\right)$} & \multicolumn{1}{c}{ Antisense $\left(5^{\prime}-3^{\prime}\right)$} \\
\hline GAPDH & GGGTGGAGCCAAACGGGTC & GGAGTTGCTGTTGAAGTCGCA \\
E-cadherin & GAACTCAGCCAAGTGTAAAAGCC & GAGTCTGAACTGACTTCCGC \\
Vimentin & AAAGTGTGGCTGCCAAGAAC & AGCCTCAGAGAGGTCAGCAA \\
$\alpha$-SMA & GGCCGAGATCTCACTGACTAC & TTCATGGATGCCAGCAGA \\
U6 & CGTTTTACTTCCTCATACAGCAC & GCACCAAGAGACCTGTGACA
\end{tabular}

$\alpha$-SMA, $\alpha$-smooth muscle actin.

A

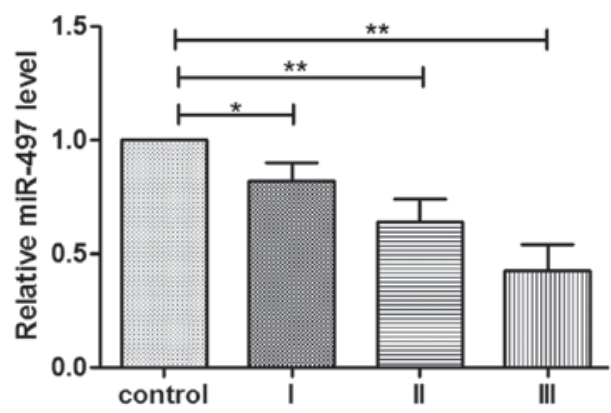

\section{B}

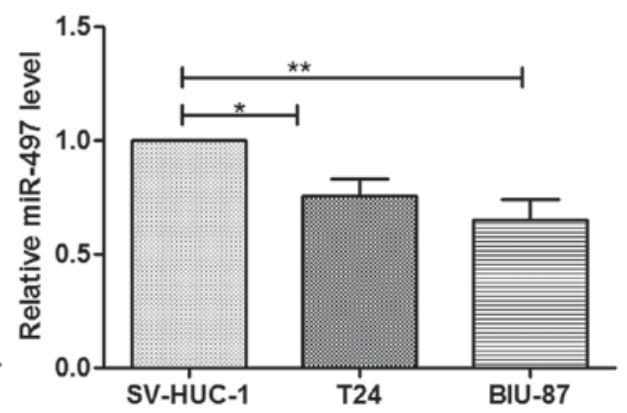

Figure 1. Expression of miR-497 in bladder cancer tissues and cell lines. (A) miR-497 expression was reduced in bladder tissues at stage I ( $=29$ ), II ( $\mathrm{n}=12$ ) and III ( $n=9)$ compared with the adjacent noncancerous tissue. The adjacent noncancerous tissues were $3 \mathrm{~cm}$ from the edge of the tumor and served as the control group ( $\mathrm{n}=50$ ). (B) The expression of miR-497 in T24 and BIU-87 cells was significantly reduced compared with $\mathrm{SV}-\mathrm{HUC}-1$ cells. ${ }^{*} \mathrm{P}<0.05$, ${ }^{* * *} \mathrm{P}<0.01$ vs. control or SC-HUC-1 cells. miR-497, microRNA-497.

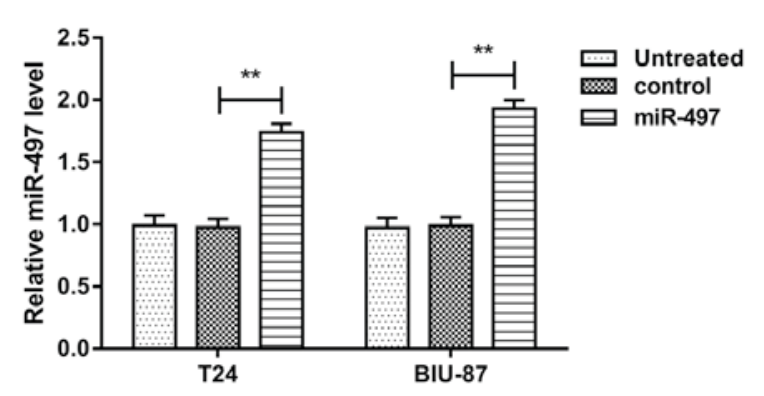

Figure 2. Expression of miR-497 in bladder cancer cells following transfection. T24 and BIU-87 cells were transfected with scramble control or miR-497 mimic. MiR-497 was upregulated after transfection with miR-497 mimic, compared with cells transfected with scramble control. ${ }^{* *} \mathrm{P}<0.01$ vs. control. miR-497, microRNA-497.

that miR-497 expression level was reduced in bladder cancer tissues compared with the adjacent noncancerous tissues and its expression was gradually reduced with increasing pathological classification stage, which was consistent with a previous study (21). In addition, the present study evaluated the association between miR-497 expression and patient characteristics, such as age, diameter of tumor, TNM stage, and pathological classification stage. Our results in Table I demonstrated that miR-497 expression was negatively associated with TNM stage, pathological classification stage and metastasis. Therefore, abnormal miR-497 expression may be associated with the tumor stage and metastasis of bladder cancer.
The effect of miR-497 expression on bladder cancer cell migration and invasion was determined using T24 and BIU-87 cells. The findings of the present study revealed that the overexpression of miR-497 significantly reduced the number of migrated and invasive cells in both cell lines. The results of the present study are consistent with previous studies performed in other cell types. Ruan et al (22) previously determined that miR-497 expression was reduced in malignant tumors, and its upregulation may inhibit cell migration in human osteosarcoma (22). Additionally, miR-497 expression modulates breast cancer invasion by targeting cyclin E1 (23). However, the association between miR-497 expression and the migration and invasion of bladder cancer cells has not been fully elucidated. Our study revealed that miR-497 upregulation may serve a suppressive role in bladder cancer metastasis through inhibition of migration and invasion.

Additionally, the present study determined the influence of abnormal miR-497 expression on metastasis-associated protein expression and the findings revealed that E-cadherin expression was increased, whereas vimentin and $\alpha$-SMA expression levels were reduced in cells overexpressing miR-497 for both cell lines. Vimentin is a cytoskeleton protein that is expressed in fibroblasts and endothelial cells. Previous studies have demonstrated that vimentin may function as a tumor marker, having an important role in cell proliferation, invasion and migration and high expression levels of vimentin induce the migration and invasion of tumor cells $(24,25)$. E-cadherin expression was low in bladder cancer cells and has been identified to be associated with tumor development and 

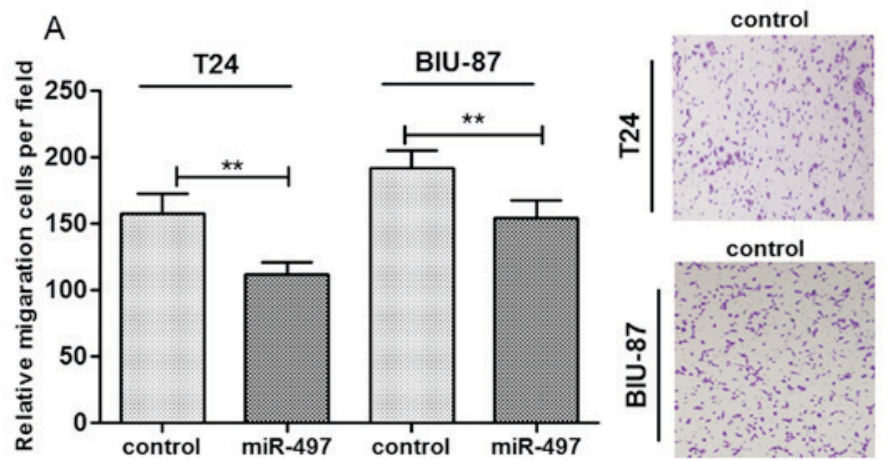

control
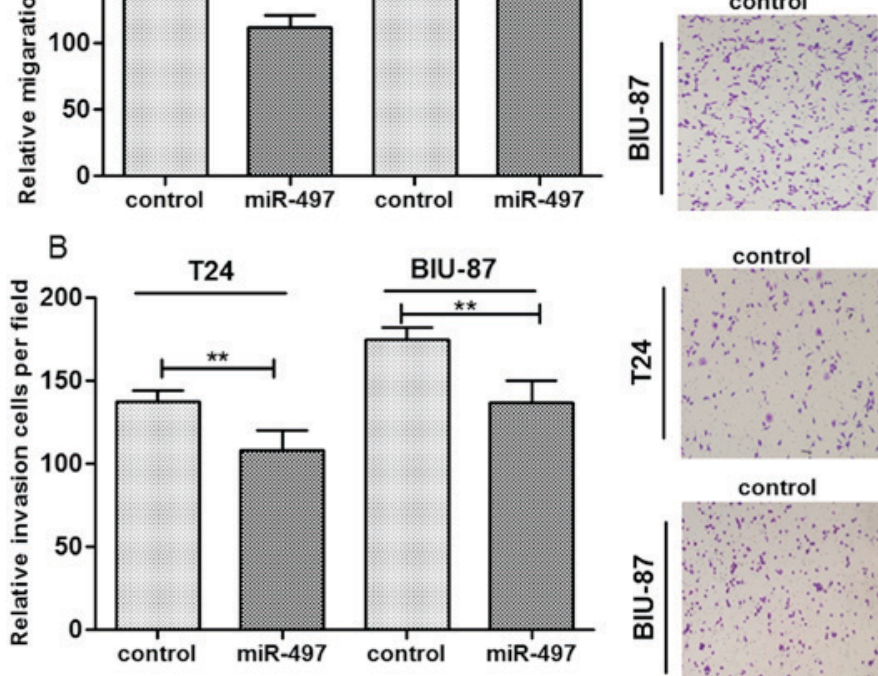

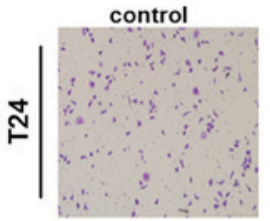

control

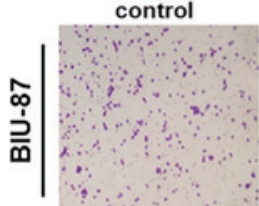

$\operatorname{miR}-497$

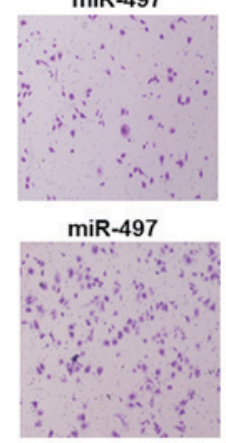

$\operatorname{miR}-497$

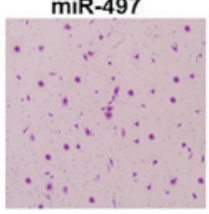

$\operatorname{miR}-497$

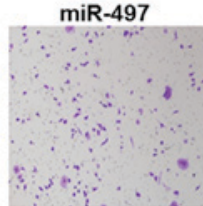

Figure 3. Effects of miR-497 on cell migration and invasion. (A) Overexpression of miR-497 reduced the number of migrated T24 and BIU-87 cells significantly compared with the control. (B) Overexpression of miR-497 reduced the number of invasive T24 and BIU-87 cells significantly compared with the control. Images were captured at a magnification of $\mathrm{x} 100$. $^{* *} \mathrm{P}<0.01$ vs. control. miR-497, microRNA-497.
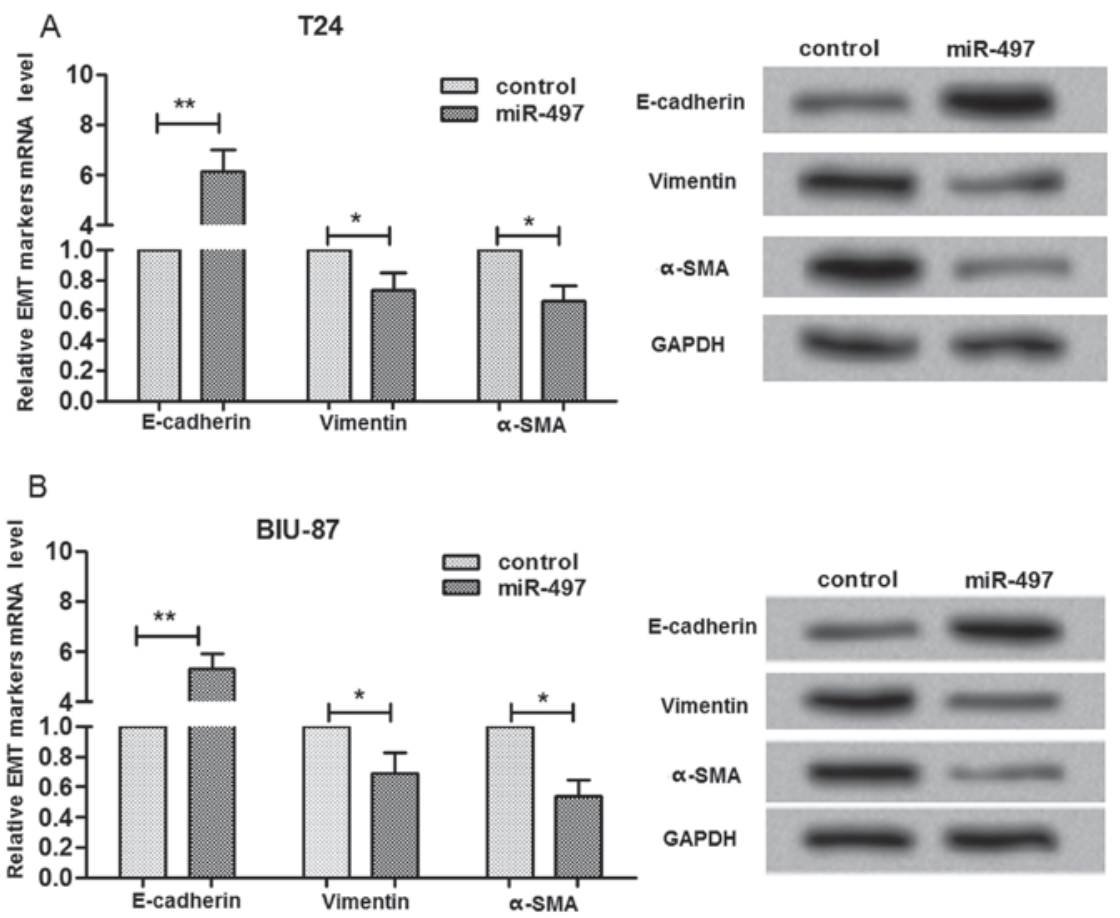

Figure 4. Influence of miR-497 on EMT-associated protein expression. mRNA and protein expression levels of E-cadherin were upregulated, whereas vimentin and $\alpha$-SMA were significantly downregulated when miR-497 was overexpressed in (A) T24 cells and (B) BIU-87 cells. $\mathrm{P}<0.05$ and ${ }^{* *} \mathrm{P}<0.01$, vs. control group. EMT, epithelial mesenchymal transition; miR-497, microRNA-497; $\alpha$-SMA, $\alpha$-smooth muscle actin.

prognosis of bladder cancer (26). $\alpha$-SMA is a key downstream factor of the serum response factor (SRF) and the combination of SRF and $\alpha$-SMA may promote the translation of mRNA (27). A previous study determined that $\alpha$-SMA participates in the development of various tumors, such as squamous cell carcinoma (28). It has been previously demonstrated that miR-133 modulates $\alpha$-SMA expression in bladder cancer (29). Additionally, E-cadherin overexpression and vimentin downregulation are markers of reduced migration and invasion in bladder cancer $(30,31)$. The findings of the present study 
revealed that miR-497 may inhibit bladder cancer cell migration and invasion through upregulation of E-cadherin and downregulations of vimentin and $\alpha$-SMA.

In conclusion, the data presented in the present study suggested that miR-497 is downregulated in bladder cancer tissues. The abnormal expression of miR-497 was associated with the metastasis of bladder cancer and miR-497 upregulation limited the metastasis of bladder cancer by affecting the expression levels of metastasis-associated proteins, such as E-cadherin, vimentin and $\alpha$-SMA. The present study may provide the theoretical basis for the application of miR-497 in diagnosing bladder cancer metastasis. Further studies are required in order to fully elucidate the underlying molecular mechanism.

\section{References}

1. Siegel RL, Miller KD and Jemal A: Cancer statistics, 2015. CA Cancer J Clin 65: 5-29, 2015.

2. Zhang $X$ and Zhang Y: Bladder cancer and genetic mutations. Cell Biochem Biophys 73: 65-69, 2015.

3. Harshman LC, Preston MA, Bellmunt J and Beard C: Diagnosis of bladder carcinoma: A clinician's perspective. Surg Pathol Clin 8: 677-685, 2015

4. Cheung G, Sahai A, Billia M, Dasgupta P and Khan MS: Recent advances in the diagnosis and treatment of bladder cancer. BMC Med 11: 13, 2013.

5. Aigner A: MicroRNAs (miRNAs) in cancer invasion and metastasis: Therapeutic approaches based on metastasis-related miRNAs. J Mol Med (Berl) 89: 445-457, 2011.

6. Zheng N, Yang P, Wang Z and Zhou Q: OncomicroRNAs-mediated tumorigenesis: Implication in cancer diagnosis and targeted therapy. Curr Cancer Drug Targets 17: 40-47, 2017.

7. Medina PP and Slack FJ: MicroRNAs and cancer: An overview. Cell Cycle 7: 2485-2492, 2008.

8. Lan G, Yang L, Xie X, Peng L and Wang Y: MicroRNA-490-5p is a novel tumor suppressor targeting c-FOS in human bladder cancer. Arch Med Sci 11: 561-569, 2015.

9. Drayton RM, Dudziec E, Peter S, Bertz S, Hartmann A, Bryant HE and Catto JW: Reduced expression of miRNA-27a modulates cisplatin resistance in bladder cancer by targeting the cystine/glutamate exchanger SLC7A11. Clin Cancer Res 20 1990-2000, 2014.

10. Yin KJ, Deng Z, Huang H, Hamblin M, Xie C, Zhang J and Chen YE: miR-497 regulates neuronal death in mouse brain after transient focal cerebral ischemia. Neurobiol Dis 38: 17-26, 2010.

11. Li D, Zhao Y, Liu C, Chen X, Qi Y, Jiang Y, Zou C, Zhang X, Liu S, Wang X, et al: Analysis of MiR-195 and MiR-497 expression, regulation and role in breast cancer. Clin Cancer Res 17 1722-1730, 2011.

12. Yan JJ, Zhang YN, Liao JZ, Ke KP, Chang Y, Li PY, Wang M, Lin JS and He XX: MiR-497 suppresses angiogenesis and metastasis of hepatocellular carcinoma by inhibiting VEGFA and AEG-1. Oncotarget 6: 29527-29542, 2015.

13. Zhang Y, Zhang Z, Li Z, Gong D, Zhan B, Man X and Kong C: MicroRNA-497 inhibits the proliferation, migration and invasion of human bladder transitional cell carcinoma cells by targeting E2F3. Oncol Rep 36: 1293-1300, 2016.
14. Du M, Shi D, Lin Y, Yuan L, Li P, Chu H, Qin C, Yin C, Zhang Z and Wang M: Circulating miR-497 and miR-663b in plasma are potential novel biomarkers for bladder cancer. Sci Rep 5: 10437, 2015.

15. Mostofi FK, Davis CJ and Sesterhenn IA: WHO histological typing of urinary bladder tumors. Springer, Berlin, 1973.

16. Union for International Cancer Control (UICC): TNM Classification of Malignant Tumours. Sobin LH and Wittekind $\mathrm{CH}$ (eds). 6th edition. John Wiley \& Sons, Hoboken, NJ, 2002.

17. Brackenbury WJ and Djamgoz MB: Nerve growth factor enhances voltage-gated $\mathrm{Na}+$ channel activity and transwell migration in Mat-LyLu rat prostate cancer cell line. J Cell Physiol 210: 602-608, 2007.

18. Lin Y, Yue B, Xiang H, Liu Y, Ma X and Chen B: Survivin is expressed in degenerated nucleus pulposus cells and is involved in proliferation and the prevention of apoptosis in vitro. Mol Med Rep 13: 1026-1032, 2016.

19. Livak KJ and Schmittgen TD: Analysis of relative gene expression data using real-time quantitative PCR and the 2(-Delta Delta C(T)) Method. Methods 25: 402-408, 2001.

20. Yan JJ, Zhang YN, Liao JZ, Ke KP, Chang Y, Li PY, Wang M, Lin JS and He XX: MiR-497 suppresses angiogenesis and metastasis of hepatocellular carcinoma by inhibiting VEGFA and AEG-1. Oncotarget 6: 29527-29542, 2015.

21. Zhu W, Zhu D, Lu S, Wang T, Wang J, Jiang B, Shu Y and Liu P: miR-497 modulates multidrug resistance of human cancer cell lines by targeting BCL2. Med Oncol 29: 384-391, 2012.

22. Ruan WD, Wang P, Feng S, Xue Y and Zhang B: MicroRNA-497 inhibits cell proliferation, migration, and invasion by targeting AMOT in human osteosarcoma cells. Onco Targets Ther 9: 303-313, 2016.

23. Luo Q, Li X, Gao Y, Long Y, Chen L, Huang Y and Fang L: MiRNA-497 regulates cell growth and invasion by targeting cyclin E1 in breast cancer. Cancer Cell Int 13: 95, 2013.

24. Zhu QS, Rosenblatt K, Huang KL, Lahat G, Brobey R, Bolshakov S, Nguyen T, Ding Z, Belousov R, Bill K, et al: Vimentin is a novel AKT1 target mediating motility and invasion. Oncogene 30: 457-470, 2011.

25. McInroy L and Määttä A: Down-regulation of vimentin expression inhibits carcinoma cell migration and adhesion. Biochem Biophys Res Commun 360: 109-114, 2007.

26. Peng RY, Zhou GH and Chun LI: Expression of E-cadherin in Bladder Cancer. Prac J Cancer 15: 87-88, 2000.

27. Kumar CC, Kim JH, Bushel P, Armstrong L and Catino JJ: Activation of smooth muscle alpha-actin promoter in ras-transformed cells by treatments with antimitotic agents: Correlation with stimulation of SRF:SRE mediated gene transcription. J Biochem 118: 1285-1292, 1995.

28. Kojc N, Zidar N, Vodopivec B and Gale N: Expression of CD34, alpha-smooth muscle actin, and transforming growth factor beta1 in squamous intraepithelial lesions and squamous cell carcinoma of the larynx and hypopharynx. Hum Pathol 36: 16-21, 2005.

29. Duan LJ, Qi J, Kong XJ, Huang T, Qian XQ, Xu D, Liang JH and Kang J: miR-133 modulates TGF- $\beta 1$-induced bladder smooth muscle cell hypertrophic and fibrotic response: Implication for a role of microRNA in bladder wall remodeling caused by bladder outlet obstruction. Cell Signal 27: 215-227, 2015.

30. Zhang M, Shan LP and Zhang H: Expression of Snail and E-cadherin in bladder urothelial carcinoma and their relation with tumor recurrence. J Mod Oncol 18: 2422-2425, 2010.

31. Lewis SA, Traub P and Spilker CM: The N-terminal domain of vimentin alters bladder permeability. J Urol 170: 2091-2094, 2003. 